\title{
Panel: Reengineering Method Engineering?
}

\author{
Panel Chair: \\ Keng Siau, University of Nebraska-Lincoln, USA \\ Panelists: \\ Lucas Introna, London School of Economics, UK \\ Graham McLeod, University of Cape Town, South Africa \\ Jeffrey Parsons, Memorial University, Canada \\ Yair Wand, University of British Columbia, Canada
}

\section{PANEL DESCRIPTION}

Is there a need for method engineering when only $20 \%$ of the developers perform modeling work? Is there a future for method engineering when the majority of practitioners subscribe to their "home-made" methods or methodologies during information systems development? These are the issues that will be discussed and argued during the panel.

Panelist Lucas Introna advocates the abandonment of the notion of method and all of its rationalistic baggage. He argues that it is not possible to train designers in particular ways of developing systems. Designers have to become apprentices to existing system developers and learn their skill by socialization. Panelist Graham McLeod maintains that methods can never be fully prescriptive, since they operate in a social environment and the behavior of a complex system is not predictable, but emergent from the complex interaction of many autonomous agents.

Panelists Jeffrey Parsons, Keng Siau, and Yair Wand, on the other hand, believe that the unfortunate state of affairs in systems development method can be attributed partly to the lack of strong theoretical foundation and empirical work in the area. In this panel, Jeff Parsons will discuss the use of classification theory (i.e., how humans organize information in terms of categories or concepts) as a theoretical foundation for method engineering. Panelist Yair Wand will discuss method engineering from the ontological point of view and show how ontological concepts can be used in method engineering. Keng Siau will address the role of empirical research in method engineering. 